Int. J. Dev. Biol. 60: 65-69 (2016)

doi: $10.1387 / \mathrm{ijdb} .150409$ th

\title{
Expressional characterization of mRNA (guanine-7) methyltransferase (rnmt) during early development of Xenopus laevis
}

\author{
ASHWIN LOKAPALLY, SANJEEVA METIKALA and THOMAS HOLLEMANN* \\ Martin-Luther-University Halle-Wittenberg, Institute for Physiological Chemistry, Halle (Saale), Germany
}

\begin{abstract}
Methylation of the guanosine cap structure at the 5' end of mRNA is essential for efficient translation of all eukaryotic cellular mRNAs, gene expression and cell viability and promotes transcription, splicing, polyadenylation and nuclear export of mRNA. In the current study, we present the spatial expression pattern of the Xenopus laevis rnmt homologue. A high percentage of protein sequence similarity, especially within the methyltransferase domain, as well as an increased expression in the cells of the transcriptionally active stages, suggests a conserved RNA cap methylation function. Spatial expression analysis identified expression domains in the brain, the retina, the lens, the otic vesicles and the branchial arches.
\end{abstract}

KEY WORDS: rnmt, methylation, 5' cap structure

Methylation is one of the most common RNA modification, which is carried out by members of the AdoMet-dependent (adenosylmethionine) methyltransferase superfamily. A member of this superfamily is the 5' mRNA (guanine-7-) methyltransferase (RNMT) (Wang and Shuman, 1997), which catalyses the addition of a 5' cap structure to the 5'-triphosphate ends of nascent nuclear pre-mRNAs shortly after transcription initiation by RNA polymerase II (RNSPII) (Shatkin, 1985). The formation of a methylated 5'-terminal cap structure m7G(5')ppp (5')N, directs the processing and transport pathways of pre-mRNA in the cell nucleus and regulates both mRNA turnover and the initiation of translation in the cytoplasm and has been studied intensively (Rottman et al., 1974; Shatkin, 1976).

The mRNA cap methyltransferase (RNMT) is highly conserved in eukaryotes and the highest similarity is maintained in the S-adenosylmethionine (SAM)-binding site necessary for catalytic activity (Saha et al., 1999; Wang and Shuman, 1997). Interestingly, the C-terminus of human RNMT could be substituted by the C-terminus of $S$. cerevisiae Abd1, the first characterized methyltransferase (Saha et al., 1999). However, mammalian RNMT has an additional non-catalytic $\mathrm{N}$-terminal domain, required for efficient recruitment of RNAPII, which is absent in yeast. The N-terminus contains 2 nuclear localization signal motifs (Aregger and Cowling, 2013) and it has been shown that nuclear localization of RNMT is essential for cell viability (Shafer et al., 2005). Yeast Abd1 and human RNMT are also required for cell growth and cell survival (Chu and Shatkin,
2008). Abd1 mutants are lethal, since inhibition of Abd1 function results in an almost complete loss of protein synthesis (Mao et al., 1996). In Xenopus oocytes, injection of synthetic RNA containing a $\mathrm{m7G}$ cap structure leads to increased stability and more efficient translation of the RNA (Gillian-Daniel et al., 1998).

It is now clear that methylation of the cap structure is necessary for the splicing of pre-mRNA, mRNA export, polyadenylation and translation initiation (Cowling, 2010). The cap methylation activity of RNMT is regulated by various factors, e.g. expression of the myelocytomatosis viral oncogene (Myc) protein leads to up-regulated mRNA cap methylation on specific target mRNAs (Cole and Cowling, 2009). Myc binds directly to a subunit of TFIIH (transcription factor $\mathrm{IIH}$ ) and increases RNAPII phosphorylation of Ser5 in the C-terminal domain (CTD), which is the binding site of RNMT during transcription initiation (Cowling and Cole, 2007). E2F1 - a transcription factor, promoting cell proliferation, was also demonstrated to up-regulate mRNA cap methylation (Cole and Cowling, 2009). SAHH (S-adenosylhomocysteine hydrolase) hydrolyses SAH (S-adenosyl homocysteine) a by-product of cellular methylation that inhibits RNMT, thus relieving suppression of RNMT activity. In line with this finding, mRNA cap methylation is up-regulated by Sahh (SAH hydrolase) during gastrulation in

Abbreviations used in this paper: RNMT, 5' mRNA (guanine-7-) methyltransferase;

\footnotetext{
*Address correspondence to: Thomas Hollemann. Martin-Luther-University Halle-Wittenberg, Institute for Physiological Chemistry, Halle (Saale), Germany. e-mail: thomas.hollemann@medizin.uni-halle.de
}

Supplementary Material (one figure) for this paper is available at: http://dx.doi.org/10.1387/ijdb.150409th

Accepted: 4 February 2016.

ISSN: Online 1696-3547, Print 0214-6282

(c) 2016 UPV/EHU Press

Printed in Spain 
Xenopus and Sahh was immunoprecipitated with Rnmt (Radomski et al., 2002).

Numerous cellular studies contributed to a better understanding of the mechanisms underlying the regulation of 5' mRNA cap methylation. Especially, extensive studies in yeast, mammalian cell cultures and in Xenopus laevis oocytes have identified many essential regulators that govern 5' capping and cap methylation. However, not much attention is paid to the developmental aspects of capping enzymes. We report on the spatio-temporal expression of Xenopus laevis mRNA (guanine-7-) methyltransferase (rnmt)

\section{A}

$$
\begin{aligned}
& \text { H. sapiens } \\
& \text { M.musculus } \\
& \text { R.norvegicus } \\
& \text { D.rerio } \\
& \text { X.tropicalis } \\
& \text { X. laevis } \\
& \text { H. sapiens } \\
& \text { M.musculus } \\
& \text { R.norvegicus } \\
& \text { D.rerio } \\
& \text { X.tropicalis } \\
& \text { X. laevis }
\end{aligned}
$$

H. sapiens

M. musculus

$R$. norvegicu
$D$. rerio

$X$. tropicalis
$X$. laevis

H. sapiens

M.musculus

R. norvegicus

D. rerio

X.tropicalis

$X$. laevis

H. sapiens

M. musculus

$R$. norvegicus

D. rerio

X.tropicalis

X. laevis

H. sapiens

M.musculus

R.norvegicus

R. norvegi
$D$. rerio

D. rerio

X. laevis

H. sapi

M. misculus

R. norvegicus

D. rerio

X.tropicalis

X. laevis

H. sapiens

M. musculus

R. norvegicus

D.rerio

X. tropicalis

$X$. laevis
61 EFEDDLVKESSSCGKDTPSKKRKLDPEIVPEEKDCGDAEGNSKKRKRETEDVPKDKSSTG 48 EFGEDLVEQNSSYVQDSPSKKRKLDVEIILEEKHSEDDGGSAKRSKLERGDVSEDEPSLG $44--Q D D L V E Q N S S Y V Q D S P S K K R K L D V E I I L D E K H S E D D G G A S K R S K L E R G G G S E D E P S P G$ ----MMAQNSRLFEMDSPYADAKVDKDSIGSSFDSSQTSTSS---------------SS --ETDVTDGPFQYVK-----_--_---_--EEHSS-------HKFTASGQNLDSPPKN --ESGGADGAFQHVK--------------GEHSS-------PKLSASEK---SLPGN

21 DGTONKRKIA----LEDVPEKOKNLEEGHSSTVAAHYNELOEVGLEKRSOSRIFYLRNFN 108 RLNOTKRKLOPODDE--VPOKLOKLEEGHSSAVAAHYNELOEVGLAKRSOSRIFYLRNFN 02 GLTERKRKLQPQDALETQTRKEQKLEEGHSSAVAAHYNELQEVGLVKRSQSRIFYLRNFN 41 SSVKRRRDGDEEDDDHSPSKKLVTEDSLHS QKVATHYNKIKECGLAERNKSRIVYMRNFN 51 KKSPLKRK----AGEPESPSKRPRLEEGHGSLVVTHYNELPETGLETRS QSRIFHLRNFN 48 TKSPL KRK----AAEPDSPPKRPRLEEGHGSLVVTHYNEL PETGLEIRSQSRIFHLRNFN 177 NWMKSVLIGEFLEKVRQKKKRDI TVIDLGCGKGGDLIKWKKGRINKLVCTDIADVSVKOC 177 NWMKSVLIGEFLEKVRQKKKRDI TVLDLGCGKGGDLIKWKKGRINKLVCTDIADVSVKQC 166 NWIKSILIGEI LEKVRQRKTRDI TVLDLGCGKGGDLIKWRKGRISRLVCADIADISMKQC 101 NWLSILIGEILEKVRQRKNREVIDLIGCGKGGDLIKWKKGRIDKLVCADIAAVSIEOC 107 NWWAATI 104 NWTKSAIGEEEKVRQR- RNIAVLDLGCGKGDLIKWRKGGISKLVCTDIADVSVKQC

$$
\star
$$
$\star \star$
ACHYSESE

237 QQRYEDMKNRR-DSEYIFSAEFITADSSKELLIDKFRDPOMCFDICSCQ 26 QQRYEDMRCRR-DNEHIFSAEFITADCSKELLVEKERDPEMYFDVCSCQFACHYSFESQV 2 QQRYEDMKCRR-DNEYIFSAEFITADCSKELIVEKFHDPEMYFDICSCQFACHYSFESLE 160 QQRYNDVRRRGHPNDRTFSAEFITADCSRELLSEKLQDPELQFDVCSCQFVYHYSFESES 166 EERYKDIKRKS-RNERVFEAEFLTADST KELLSEKYNDPEIKFDICSCQFVYHYSFETYE 163 EQRYKDMKRKS-RNERIFEAEELTSDSTKELLSEKYIDPEIKFDICSCQFVYHYSFETYE

96 QADMMLRNACERLSPGGYFIGTT PNSEELIRRLEASETESEGNE IYTVKFQKKGDYPLFG 285 OADTMLRNACGRLNPGGYFIGTTPNSFELIRRLEASETESFGNEIYTVKFOKKGNYPIFG

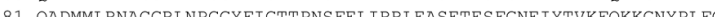
作 220 2 ADCMLNACERLRGG Q225 QADMLRNACERLCPGGETGITPDGELVKRLEASDINSEGNDVYMKEEKKGKYPLFG

356 CKYDFNLEGVVDVPEFLVYFPLINEMAKKYNMKLVYKKTF LEFYEEKIKNNENKMLLKRM 345 CKYDFNLEGVVDVPEFLVYEPLLTEMAKKYNMKLIYKKTFLEFYEEKIKNNENKMLLKRM 341 CKYDFNLEGVVDVEFLVYFPLLTEMAKKYNMKLIYKKTFLE FYEEK IKNNENKMLLKRM 280 CQYDFSLEGVVNVPEFLVYFP LFVEMAKKYNMRLVYKKTFKEFFEEKVKDGKNKDLMQWM 85 CKYDFSLEEVVNVPEFLVYEPVLVEMAKKYQMKLIYKKTFREFEEEKVKNDEQKMLLKRM 282 CKYDFSLEEVVNVPEFLVYFPVLVEMAKKYOMKLIYKKTFREFFEEKVKNDEQKMLLKRM

416 QALEPYPANESSKLVSEKVDDYEHAAKYMKNSQVRLPLGTLSKSEWEATSIYLVEAFEKQQ 476678 405 QALEQYPAHENSKLASEKVGDYTHAAEYLKKSQVRLPLGTLSKSEWEATSIYLVEAFEKQQ $46569 \%$ 05 QALEQYAHE 01 QALESYPANENSKIASEKAGDYAHAAEYMKNSQVRLPLGILSKSENEATSIYLVAFEKQQ $46174 \%$ 340 QALEQYPPDERGQLSSSGPGEYDHAKRKAADPAVRRPLGTLSKSEWEATSIYLVYVEEKMS $40064 \%$ 345 KALEPYPAAPNFKLVSGRTEDYEHAQKLVENGQVKLPLGTLSKSEWEATSIYLLEAFEKQA $40590 \%$
342 KALESYPAAPNTKLVSGRTEDYEHAQKMVENGQIKLPLGTLSKSEWDATSIYLLFAFEKQA $402100 \%$

C

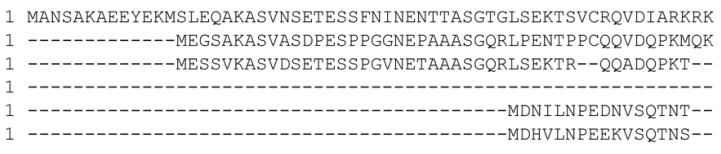

during early development.

\section{Results and Discussion}

\section{Sequence analysis and evolutionary relationship}

We identified an expressed sequence tag (EST) containing the full-length Xenopus laevis RNA (guanine-7-) methyltransferase (rnmt) sequence using the BLAST programme. A full-length clone was obtained from the I.M.A.G.E. consortium, Source Biosciences (NM_001088535.1) and used in this study. The 1959 bp full-length

B
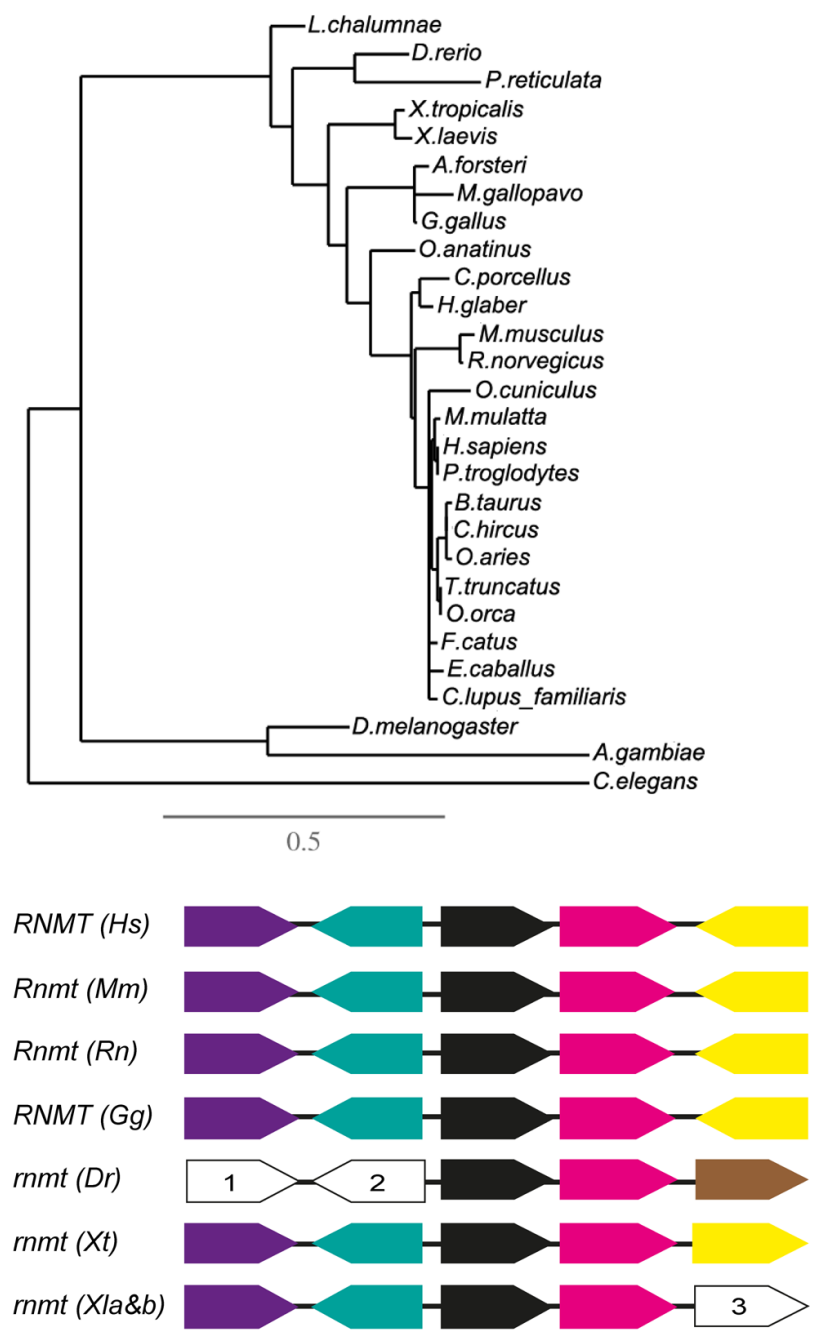

Fig. 1. Alignment of vertebrate Rnmt protein sequences. (A) Comparison of amino acid sequences of vertebrate Rnmt. H. sapiens (GenBank Accession no. NP_003790), M. musculus (GenBank Accession no. NP_080716), R. norvegicus (GenBank Accession no. NP_001008300), D. rerio (GenBank Accession no. NP_001038465), X. tropicalis (GenBank Accession no. NP_001017053), X. laevis (GenBank Accession no. NP_001082004). The nuclear localization signal motifs are highlighted in blue, while the SAM (S-adenosylmethionine) binding domain is highlighted in yellow. The stars above the sequence indicate the amino acids necessary for the methyl transferase activity of RNMT. Sequence identities compared to the X. laevis protein in percent are indicated at the end of the alignment. (B) Phylogenetic analysis: The common ancestral node indicates orthology among species. The bar at the bottom of the phylogram indicates the evolutionary distance, to which the branch lengths are scaled based on the estimated divergence. There is a $50 \%$ relative divergence observed over time. (C) Synteny analysis of rnmt. The location and orientation of rnmt in the respective genomes is conserved. Each arrow stands for a single gene while the arrowhead indicates the direction of the ORF. Orthologues are marked with identical colours. rnmt (black arrow) is present in all the species analysed. The genes flanking rnmt downstream are identical in all species except for D. rerio where the identity of the flanking genes (1 \& 2) is still unknown. Similarly, the genes flanking rnmt upstream are identical in all species other than D. rerio (brown arrow) and $X$. laevis (3) with unknown identity. Arrow colours; black: rnmt, turquoise: family with sequence similarity 210 member Afam210a, violet: low-density lipoprotein receptor class A domain containing 4/dlrad4, pink: melanocortin 5 receptor/mc5r, yellow: melanocortin 2 receptor/mc2r, brown: collagen triple helix repeat containing 1a/cthrc1a, white 1,2 \& 3: unknown identity. 
A

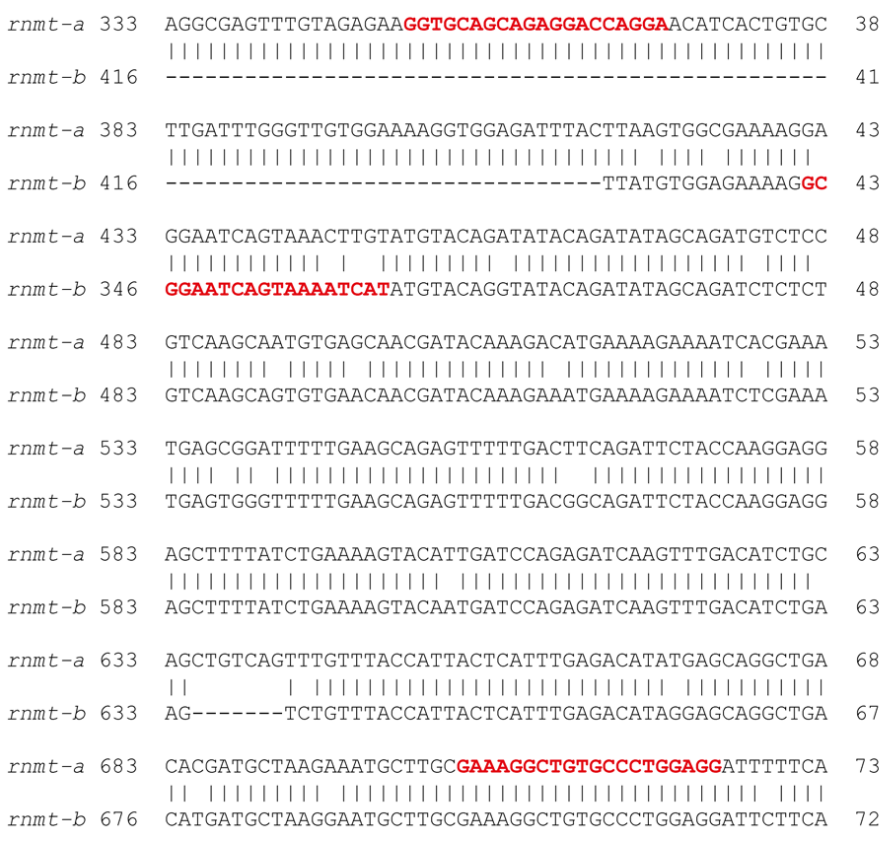

B

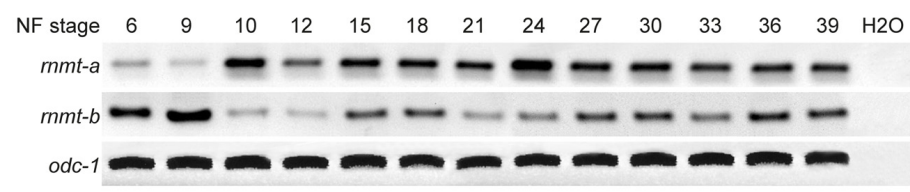

C

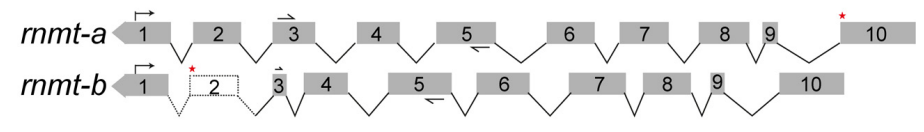

Fig. 2. Temporal expression and comparison of $r n m t$ paralogs. (A) The nucleotide sequence of the fragment used to compare spatial expression of $r n m t-a$ and -b is shown. Sequences used for primer pairs are in red. Intron spanning primers were used to exclude any contamination from genomic DNA. Primer pairs, specific to each of both loci were used to compare the temporal expression of the paralogs. (B) Semi-quantitative rt-PCR revealed zygotic expression of rnmt-a, whereas rnmt-b shows maternal presence. Housekeeping gene ODC1 was used as a control for equal RNA input. (C) Genomic profile of both the loci ' $a$ ' and ' $b$ '. Grey boxes indicate exons and lines joining them the intronic regions of the gene. Forward arrow represent the start codon while star the stop codon. Arrowheads over exons represent the PCR primer pairs used in this study. Note the missing genomic sequence is shown in dotted lines between exon 1 and exon 3 and including the whole exon.

rnmt cDNA sequence contains an ORF of 1209 bases, encoding a putative protein of 402 amino acids. The alignment of the predicted amino acid sequences of known homologues reveals high similarity in the region essential for RNA (guanine-7-) methyltransferase activity $(100 \%)$. The similarity over the whole length of the protein is $>65 \%$ among vertebrates (Fig. $1 \mathrm{~A}$ ). It is important to note that the length and sequence of different $\mathrm{N}$-terminal regions differs substantially (Fig. 1A). In human RNMT, the $\mathrm{N}$-terminal residues 1 to 120 are dispensable for enzymatic activity but they are necessary for the recruitment of RNMT to the transcription initiation site (Aregger and Cowling, 2013) and for nuclear localization of the methyltransferase (Fig. 1A) (Shafer et al., 2005). However, Xenopus Rnmt, has a shorter N-terminus, lacking the two nuclear localization signal (NLS) motifs present in the human protein. It has been shown that a third NLS motif at K126 of the human protein sequence is sufficient for alternative nuclear localization (Shafer et al., 2005). This NLS motif is also present in the Xenopus laevis protein at position K53. Similarly, the SAM (S-adenosylmethionine) binding site as well as the sites necessary for methyltransferase activity are well conserved between mammals and amphibians (Fig. 1A) (Bujnicki et al., 2001; Saha et al., 1999). Further, we identified the sequence of a paralogue (rnmt-b) within the Xenopus laevis genome. Sequence comparison of the paralogues revealed a large un-sequenced region, which lies between the first and the third exon including exon 2 (Fig. 2C). A search for Xenopus laevis EST clones lead to the identification of a cDNA sequence, encoding a truncated protein (Supplementary Fig. S1) thus making it difficult for any further analysis.

A phylogenetic tree was constructed for the identified proteins from vertebrates based on maximum likelihood using phylogeny.fr. The branches originate from a phylogenetically common ancestral lineage (Fig. 1B). Varying lengths of protein sequences contribute to the length of branches over the course of evolution. The phylo- genetic groups correlate well with the presence of the sequence signatures that can be regarded as synapomorphies (shared features derived from a common ancestor). To further confirm orthology of Xenopus rnmt, we looked at the synteny. Xenopus laevis rnmt shows a shared synteny among the species analysed (Fig. 1C). However, the orientation of the second gene (brown and yellow arrows and 3) upstream to rnmt in lower vertebrates differs from that of higher vertebrates, due to a possible shift in orientation of the respective genes.

\section{Temporal expression of Xenopus laevis (guanine-7) methyl- transferase (rnmt) during early development}

To analyse the temporal expression of both paralogues of Xenopus rnmt during early embryogenesis, we designed two primer pairs, each pair specific for only one of the two loci ( $a$ and $b$ ). Using semi-quantitative RT-PCR we could detect relatively low maternal expression of $r n m t-a$ at the earliest developmental stage analysed (NF stage 6). At gastrulation (NF stage 10), expression of rmnt-a is slightly upregulated, due to the initiation of zygotic expression (Fig. 2B). The expression level remains constant throughout further stages. In contrast, much stronger maternal expression of $r n m t-b$ is detectable, but during gastrulation expression decreases and remains relatively low during later development. This temporal expression pattern is in contrast to the earlier reported expression (Yokoska et al., 2000, Liu et al., 2014), wherein the expression is shown only up to stage 20, with expression levels of $r n m t$ gradually decreasing after gastrulation. Interestingly, later studies reported an upregulation of mRNA cap methylation during oocyte maturation (Gillian-Daniel et al., 1998), probably an indirect effect of sahh. sahh hydrolyses sah; an inhibitor of rnmt, thus relieving the repression of the methyltransferase. During early gastrulation sahhtranslocates from the cytoplasm to the nucleus, coinciding with the increase in zygotic mRNA synthesis and thereby the expres- 
sion of $r n m t$ (Radomski et al., 1999, 2002). We observed a similar regulation of rnmt-a but not of $r n m t-b$ at gastrulation suggesting differential expression of both isoforms. Although, the 5'UTR is similar in both isoforms, the 3'UTR differs hugely. Also reported earlier, the human isoforms of RNMT, hCMT1a, -b and -c, hCMT1a and hCMT1c encode for the same protein but the 5' and 3' UTR regions of hCMT1a differs from $\mathrm{hCMT1c}$, while hCMT1b shares the same N-terminus as hCMT1c but differs thereafter. Recombinant $\mathrm{hCMT1} 1 \mathrm{a} / \mathrm{c}$ are active in an in vitro RNA methyltransferase assay, whereas hCMT1b is not (Tsukamoto et al., 1998). This leads to
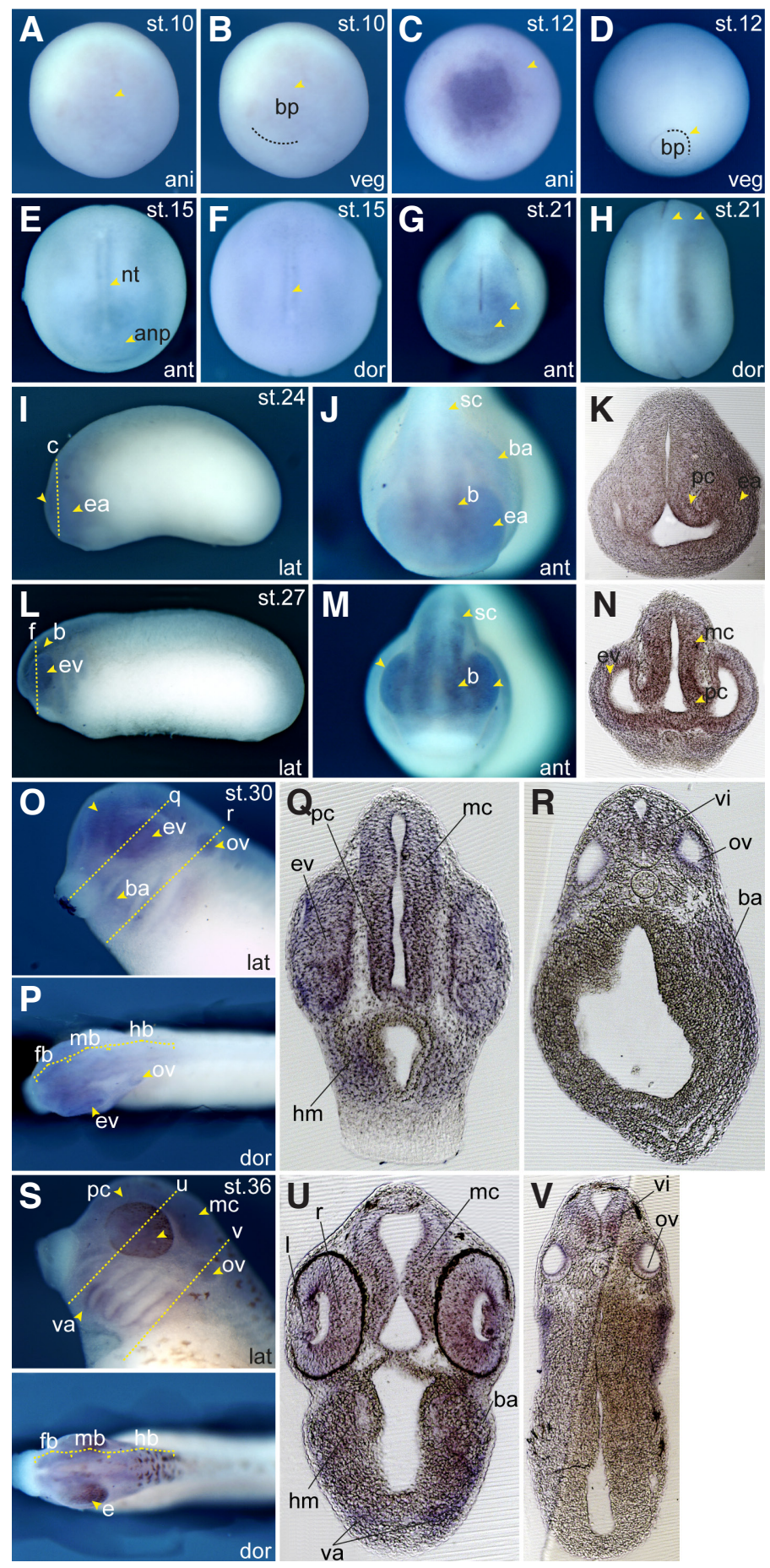

the hypothesis that, a similar differential regulation of Rnmt among the active and non-active isoform exists here for Xenopus laevis rnmt-a and rnmt-b. Radomski et al., (1999) proposed earlier that efficient cap methylation of mRNA requires the expression of $r n m t$ in transcriptionally active cells. We also see a similar increased expression of the transcript from gastrulation onwards.

\section{Spatial expression of Xenopus laevis mRNA (guanine-7) methyltransferase (rnmt) during early development}

Since the spatial expression of rnmt during early Xenopus development is not analysed yet, we examined the spatial expression of RNA (guanine-7-) methyltransferase in frog embryos using whole mount in situ hybridization. Due to lack of complete rnmt-b sequence and its high similarity towards locus-a, it was not possible to generate an in situ probe for the -b locus. Transcripts of rnmt are weakly detected early in the animal hemisphere of blastulae (data not shown). At gastrulation (Fig. 3A-D), rnmt transcripts were detected in the ectoderm of the animal hemisphere. At early and late neurula stages expression of $r n m t$ was restricted to the anterior neural plate, the neural folds (Fig. $3 \mathrm{E}-\mathrm{H}$ ) and the eye anlage.

From early to late tailbud stages (Fig. $3 \mathrm{I}-\mathrm{N}$ ) rnmt transcripts were detected in prospective brain areas, i.e. proscencephalon, mesencephalon and rhombencephalon, the retinal layers of eye vesicles and the branchial arches. Furthermore, at late tailbud stages, rnmt transcripts are also expressed in the otic vesicle (Fig. $3 \mathrm{O}-\mathrm{V}$ ), in the lens, head mesenchyme (hm) (Fig. $3 \mathrm{Q}, \mathrm{R}$ ), ventral aorta (va) (Fig. $3 \mathrm{U}$ ) and the ventral interneuron (vi) region of the hindbrain (Fig. $3 \mathrm{R}, \mathrm{V}$ ). The functional role of this gene in transcriptional hierarchy of RNA cap methylation during develop-

Fig. 3. Spatial expression of rnmt. Whole-mount in situ hybridization of wild type albino embryos at developmental NF stages 10 to 21. At gastrulation; stage 10 and 12, transcripts of rnmt are visible in the animal hemisphere but not in the vegetal (blastopore) (yellow arrowheads; $A-D$ ). During early and late neurulation transcripts are detectable in the anterior neural plate (anp), and the neural tube (nt) (E-H). At stage 21 transcripts were detected in the prospective eye anlage $(G, H)$. (I-L) rnmt expression during embryonic development. $(\mathbf{I}, \mathbf{J})$ Lateral and anterior view of an embryo at stage 24. rnmt transcript were detectable in the eye anlage (ea) and brain (b) The expression in the branchial arches (ba) and the spinal cord (sc) isrelatively weak. (L,M) Lateral and anterior view of an embryo at stage 27. Similar to stage $24 \mathrm{rnmt}$ is detectable in the brain (b) eye vesicle (ev), the spinal cord (sc) and the branchial arches (ba). (K,N) Transverse sections of stage 24 and stage 27 embryos show expression in the eye vesicle (ev), procencephalon (pc) and mesencephalon (mc). (O-T) Expression of rnmt during late tail bud stages. (0) Lateral view of the head of a stage 30 embryo. rnmt is expressed in the eye vesicle (ev), otic vesicle (ov) and the branchial arches (ba). Yellow dotted lines indicate the level of sections shown in e \& f. (P). Dorsal view of stage 30 embryo. Expression in forebrain ( $\mathrm{fb}$ ) and midbrain ( $\mathrm{mb}$ ) is visible, while a weak expression is seen in hind brain (hb). (S). Lateral view of the head of a stage 36 embryo. rnmt mRNA is localized in the neural system, ventral branchial arches and ventral aorta. Yellow dotted lines indicate the level of sections shown in $G \& H$. (T). Dorsal view of stage 36 embryo. rnmt mRNA transcript is visible in eyes and the brain region. $(\mathbf{Q}, \mathbf{R}, \mathbf{U}, \mathbf{V})$. Transverse sections through Xenopus embryos at indicated stages. (Q) $\mathrm{rnmt}$ is expressed in the eye vesicle (ev), prosencephalon (pc), mesencephalon (mc) and head mesenchyme (hm). (R) rnmt expression can be viewed in inter neuronal region of the hind brain (hb), otic vesicle (ov) and branchial arches (ba). (U). rnmt is expressed in mid brain ( $\mathrm{mc})$, retina (r), lens (I), head mesenchyme ( $\mathrm{hm})$, branchial arches (ba) and ventral aorta (va). (V) rnmt expression is seen in ventral inter neurons (vi) of the hind brain and the otic vesicle (ov). 
ment needs to be further established. It is of note that Xp54nrb, another RNA processing enzyme involved in splicing was reported to be expressed in neural structures recently (Neant et al., 2001).

Concluding, this paper describes the expression of a vertebrate RNA cap methylation enzyme expressed in early development of Xenopus laevis. Our data shows that rnmt is expressed in a restricted pattern, specifically in the developing brain, the retina, the lens, the otic vesicles and the branchial arches.

\section{Materials and Methods}

\section{Experimental model}

Albino Xenopus laevis frogs were purchased from Nasco (Ft. Atkinson, $\mathrm{WI})$. Production and rearing of embryos was performed as described earlier (Hollemann and Pieler, 1999) and staged according to Nieuwkoop and Faber, 1994.

\section{Whole mount in situ hybridization}

Whole mount in situ hybridization was performed as described (Hollemann et al., 1998). Anti-sense xl-rnmt RNA probe was transcribed in the presence of digoxigenin-labelled UTP (Roche) from plasmid $x$ l-rnmt/ pCMV-Sport6.ccdb (Sacl/T7). Chromogenic reactions were carried out using NBT/BCIP (Roche). Embryos were photographed after the chromogenic reaction. $30 \mu \mathrm{m}$ sections were cut from embryos embedded in gelatin/ albumin using a microtome (Leica, Germany) and mounted on glass slides.

Total RNA extraction, cDNA preparation and semi-quantitative RT-PCR Total RNA was extracted from snap frozen embryos. Embryos were homogenized in TRIZOL, and phase separated using chloroform. The mixture was centrifuged and re-extracted using chloroform. Total RNA was precipitated using isopropanol and re-suspended in RNase free water. 500 ng total RNA was used for cDNA synthesis using Protoscript II RTase (NEB) and random primers following manufacturer's protocol. Semi-quantitative RT-PCR was performed using following intron spanning primer pairs, rnmt-a: 5'-GGTGCAGCAGAGGACCAGGA and CCTCCAGGGCACAGCCTTTC, rnmt-b: 5'- GGCGGAATCAGTAAAATCAT and reverse same as above. Annealing temperatures were $62^{\circ} \mathrm{C}$ and $56^{\circ} \mathrm{C}, 28$ and 32 cycles respectively. $x l$-odc- 1 was used to control the input mRNA $\left(56^{\circ} \mathrm{C}, 26\right.$ cycles).

\section{Alignment, phylogeny, synteny}

The fasta sequences for the protein families analysed were obtained by Blast tool (http://blast.ncbi.nlm.nih.gov) and aligned using T-Coffee and Box shade tool (http://tcoffee.vital-it.ch/apps/tcoffee/index.html). A phylogenetic tree of the proteins was generated through maximum-likelihood using one-click mode (http://www.phylogeny.fr). The synteny analysis is based on data derived with the help of metazome v3.0 (http://www.metazome. com). The individual gene sequences and the corresponding information regarding Xenopus laevis gene loci were obtained from Xenbase (http:// gbrowse.xenbase.org) and depicted accordingly.

\section{References}

AREGGER M, COWLING V H (2013). Human cap methyltransferase (RNMT) Nterminal non-catalytic domain mediates recruitment to transcription initiation sites. Biochem J 455: 67-73.

BUJNICKI J M, FEDER M, RADLINSKA M and RYCHLEWSKI L (2001). mRNA: guanine-N7 cap methyltransferases: identification of novel members of the family, evolutionary analysis, homology modeling, and analysis of sequence-structurefunction relationships. BMC Bioinformatics 2: 2.

CHU C, SHATKIN A J (2008). Apoptosis and Autophagy Induction in Mammalian Cells by Small Interfering RNA Knockdown of mRNA Capping Enzymes. Mol Cell Biol 28: 5829-5836.

COLE M D, COWLING V H (2009). Specific regulation of mRNA cap methylation by the c-Myc and E2F1 transcription factors. Oncogene 28: 1169-1175.

COWLING VH (2010). Regulation of mRNAcap methylation. Biochem J 425: 295-302.

COWLING V H, COLE M D (2007). The Myc Transactivation Domain Promotes Global Phosphorylation of the RNA Polymerase II Carboxy-Terminal Domain Independently of Direct DNA Binding. Mol Cell Biol 27: 2059-2073.

GILLIAN-DANIEL D L, GRAY N K, VAASTRÖM J, BARKOFF A and WICKEN M (1998). Modifications of the 5' Cap of mRNAs during Xenopus Oocyte Maturation: Independence from Changes in Poly (A) Length and Impact on Translation. Mol Cell Biol 18: 6152-6163.

HOLLEMANN T, PIELERT (1999). Xpitx-1: a homeobox gene expressed during pitutary and cement gland formation of Xenopus embryos. Mech Dev 88: 249-252.

HOLLEMANN T, CHEN Y, GRUNZ H and PIELER T (1998). Regionalized metabolic activity establishes boundaries of retinoic acid signalling. EMBOJ17:7361-7372.

LIU M M, DAVEY J W, JACKSON D J, BLAXTER M L and DAVISON A (2014). A conserved set of maternal genes? Insights from a molluscan transcriptome. Int $J$ Dev Biol 58: 501-511

MAO X, SCHWER B and SHUMAN S (1996). Mutational analysis of the Saccharomyces cerevisiae ABD1 gene: cap methyltransferase activity is essential for cell growth. Mol Cell Biol 16: 475-480.

NEANT I, DEISIG N, SCERBO P, LECLERC C and MOREAU M (2011). The RNAbinding protein Xp54nrb isolated from a Ca2+-dependent screen is expressed in neural structures during Xenopus laevis development. Int J Dev Biol, 55: 923-931

RADOMSKI N, KAUFMANN C and DREYER C (1999). Nuclear Accumulation of S-Adenosylhomocysteine Hydrolase in Transcriptionally Active Cells during Development of Xenopus laevis. Mol Biol Cell 10: 4283-4298.

RADOMSKI N, BARRETO G, KAUFMANN C, YOKOSKA J, MIZUMOTO $\mathrm{K}$ and DREYER C (2002). Interaction of S-adenosylhomocysteine hydrolase of Xenopus laevis with mRNA (guanine-7-) methyltransferase: implication on its nuclear compartmentalisation and on cap methylation of hnRNA. Biochim Biophys Acta 1590: 93-102.

ROTTMAN F, SHATKIN A J and PERRY R P (1974). Sequences Containing Methylated Nucleotides at the 5' Termini of Messenger RNAs: Possible Implications for Processing. Cell 3: 197-199.

SAHAN, SCHWER B and SHUMAN S (1999). Characterization of human, Schizosaccharomyces pombe, and Candida albicans mRNA cap methyltransferases and complete replacement of the yeast capping apparatus by mammalian enzymes. $J$ Biol Chem 274: 16553-16562.

SHAFER B, CHU C and SHATKIN A J (2005). Human mRNA Cap Methyltransferase: Alternative Nuclear Localization Signal Motifs Ensure Nuclear Localization Required for Viability. Mol Cell Biol 25: 2644-2649.

SHATKIN A J (1976). Capping of Eukaryotic mRNAs. Cell 9: 645-653.

SHATKIN A J (1985). mRNA cap binding proteins: essential factors for initiating translation. Cell 40: 223-224.

TSUKAMOTO T, SHIBAGAKI Y, NIIKURA Y and MIZUMOTO K (1998). Cloning and Characterization of Three Human cDNAs Encoding mRNA (Guanine-7-)methyltransferase, an mRNA Cap Methylase. Biochem Biophys Res Commun 251: 27-34

WANG S P, and SHUMAN S (1997). Structure-function analysis of the mRNA cap methyltransferase of Saccharomyces cerevisiae. J Biol Chem 272: 14683-14689.

YOKOSKA J, TSUKAMOTO T, MIURA K, SHIOKAWA K and MIZUMOTO K (2000). Cloning and Characterization of mRNA Capping Enzyme and mRNA (Guanine7-)-methyltransferase cDNAs from Xenopus laevis. Biochem Biophys Res Commun 268: 617-624. 


\section{Further Related Reading, published previously in the Int. J. Dev. Biol.}

Activin ligands are required for the re-activation of Smad2 signalling after neurulation and vascular development in Xenopus tropicalis

Yuki Nagamori, Samantha Roberts, Marissa Maciej and Karel Dorey

Int. J. Dev. Biol. (2014) 58: 783-791

http://www.intjdevbiol.com/web/paper/140244kd

A conserved set of maternal genes? Insights from a molluscan transcriptome

M. Maureen Liu, John W. Davey, Daniel J. Jackson, Mark L. Blaxter and Angus Davison

Int. J. Dev. Biol. (2014) 58: 501-511

http://www.intjdevbiol.com/web/paper/140121ad

Xenopus cadherin $\mathbf{5}$ is specifically expressed in endothelial cells of the developing vascular system

Herbert Neuhaus, Sanjeeva Metikala and Thomas Hollemann

Int. J. Dev. Biol. (2014) 58: 51-56

http://www.intjdevbiol.com/web/paper/140013hn

AP-1C-Jun/FosB mediates xFoxD5b expression in Xenopus early developmental neurogenesis

Jaeho Yoon, Jung-Ho Kim, Ok-Joo Lee, Sung-Young Lee, Seung-Hwan Lee, Jae-Bong Park, Jae-Yong Lee, Sung-Chan Kim and Jaebong Kim

Int. J. Dev. Biol. (2013) 57: 865-872

http://www.intjdevbiol.com/web/paper/130163jk

Brachyury, Tbx2/3 and sall expression during embryogenesis of the indirectly developing polychaete Hydroides elegans

Cesar Arenas-Mena

Int. J. Dev. Biol. (2013) 57: 73-83

http://www.intjdevbiol.com/web/paper/120056ca

xCOUP-TF-B regulates xCyp26 transcription and modulates retinoic acid signaling for anterior neural patterning in Xenopus

Misaki Tanibe, Sho-Ichi Ishiura, Makoto Asashima and Tatsuo Michiue

Int. J. Dev. Biol. (2012) 56: 239-244

http://www.intjdevbiol.com/web/paper/113482mt

The RNA-binding protein Xp54nrb isolated from a Ca2+-dependent screen is expressed in neural structures during Xenopus laevis development

Isabelle Neant, Nina Deisig, Pierluigi Scerbo, Catherine Leclerc and Marc Moreau Int. J. Dev. Biol. (2011) 55: 923-931

http://www.intjdevbiol.com/web/paper/103253in

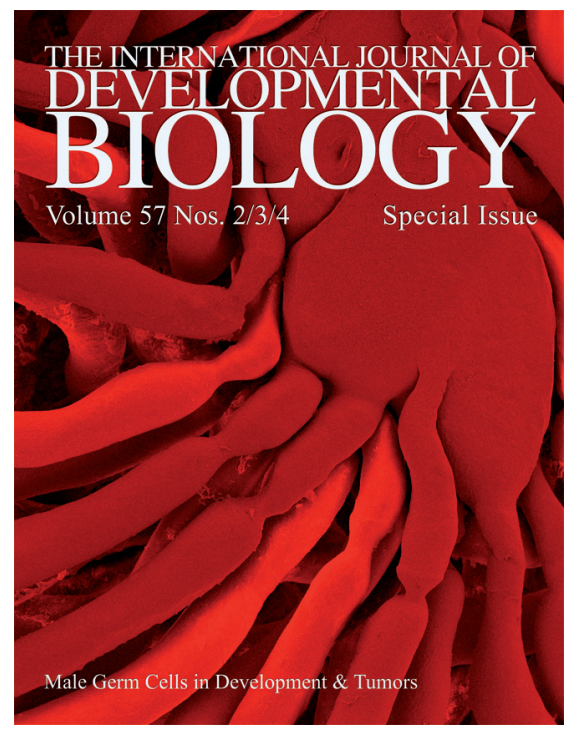

5 yr ISI Impact Factor $(2013)=2.879$
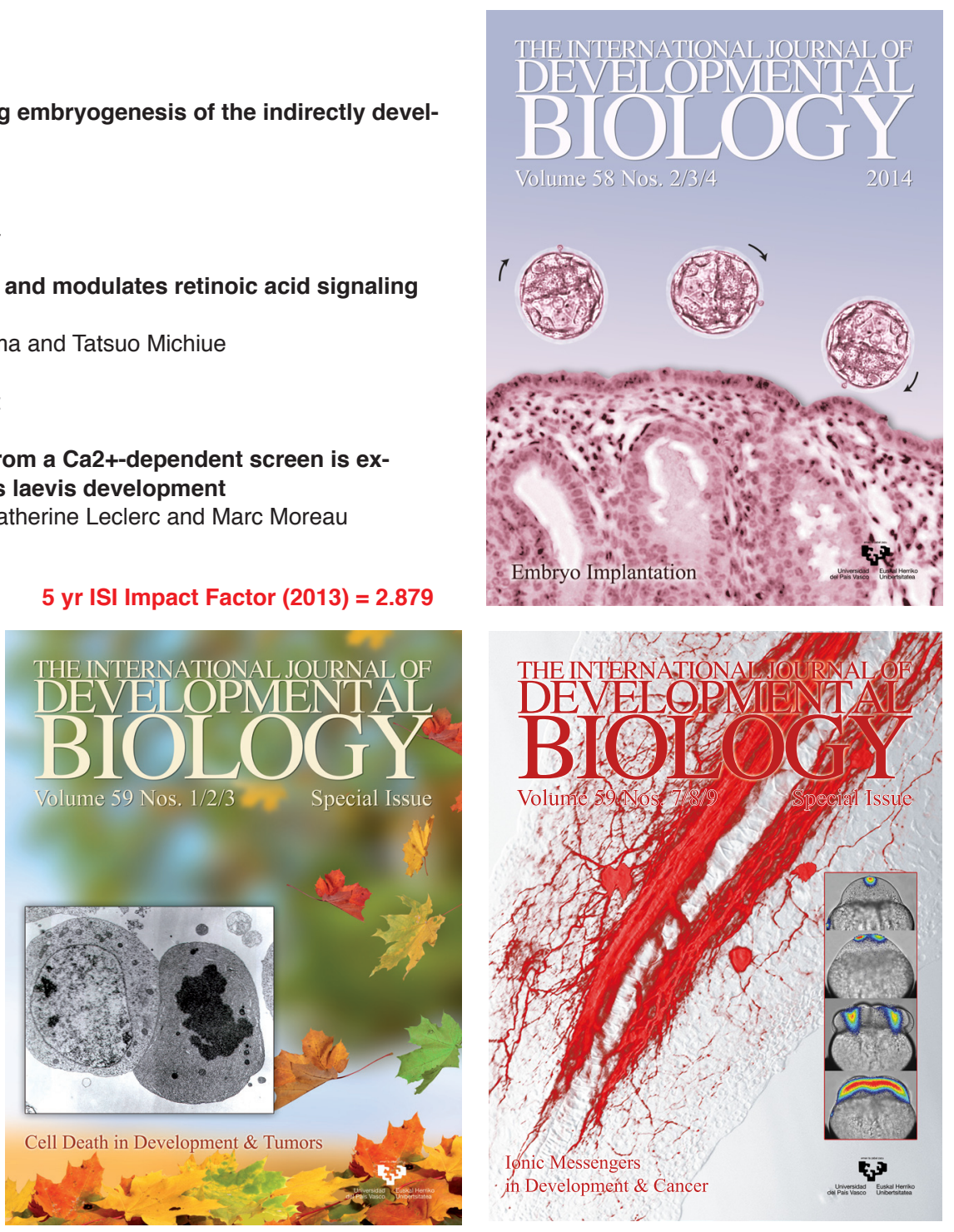